handling (29.5\%, out of 1811), hand-arm vibrations (13.9\%), repetitive movements of the upper limb (10.9\%), whole-body vibrations (7.6\%), awkward posture of the upper limb (7.1\%), and awkward body posture (4.5\%).

Discussion The exposure to biomechanical overload seems to play a role in generating potentially work-related conditions. Expanding the MAREL network to other occupational disease consultation centres in 2017 and 2018, we will contribute to already existing surveillance systems (i.e. MALPROF) by the detection of new and emerging occupational diseases and risks.

\section{AN AUDIT ON THE QUALITY OF MANAGEMENT REFERRALS TO OCCUPATIONAL HEALTH SERVICE}

1,2 Zakiah Amir*, 'Deborah Moriarty, ${ }^{2}$ Sibeal Carolan, ${ }^{2}$ Lynda Sisson. ${ }^{1}$ Occupational Health Department, Connolly Hospital Blanchardstown, Dublin, Ireland; ${ }^{2}$ HSE Workplace Health and Wellbeing Unit, Dublin, Ireland

\subsection{6/oemed-2018-ICOHabstracts. 1075}

Introduction Managers may refer their workers for occupational health $(\mathrm{OH})$ assessment when there is concern about their workers' health. To benefit from $\mathrm{OH}$ services, referrals need to include necessary information to enable $\mathrm{OH}$ professionals carrying out assessment and communicate information back. The national management referral form has been designed for this purpose. The aim of this audit is to analyse management's compliance to this form.

Methods Ten random new management referral forms received in May 2017 were pulled and analysed under ten separate headings;

1. Employee details,

2. post details,

3. job demands,

4. current medical issues,

5. sickness absence grid,

6. reason for referral,

7. description of main issues and relevant facts,

8. specific advise requested,

9. manager's details and

10. employees consent.

Data obtained was analysed using Excel Spreadsheet. Each completed headings were scored ten and zero score was given for incomplete heading. The results were totalled and given a final score in percentage value. The headings were further broken down into five aspects for analysis:

- Legal (consent),

- Demands of duty to better inform $\mathrm{OH}$ (post details and job demands),

- Effect of health issues to work (current medical issues and sickness absence grid),

- Manager's concern (reason for referral, describe the main issues and relevant facts, specific advise requested), and

- Communication (employee's and manager's details).

Result Total manager's compliance was $79.8 \%$. Compliance to legal aspect was 40\%. Compliance to provide information regarding demands of duty to better inform the $\mathrm{OH}$ was $90 \%$. Compliance to provide information regarding effect of health to work was $85 \%$. Compliance to provide information to aid communication was $70 \%$. Compliance to provide information to address manager's concerns was $100 \%$.
Discussion Management's general compliance to the national management referral form was good. Specific aspects of manager's referral can be further improved. Results were discussed at service user's forum and a re-audit is planned in the future.

\section{SURVEY ON HEALTH INTERVIEW SHEETS FOR ANNUAL HEALTH CHECKUPS IN JAPAN}

${ }^{1}$ Hajime Ando*, ${ }^{1}$ Kazunori Ikegami ${ }^{1}$ Ryosuke Sugano, ${ }^{1}$ Satoshi Michii, ${ }^{1}$ Taiki Shirasaka, ${ }^{1}$ Akira Ogami, ${ }^{2}$ Tasuku Tadano. 'Dept of Work Systems and Health, University of Occupational and Environmental Health, Japan; ${ }^{2}$ National Federation of Industrial Health Organisation, Tokyo, Japan

\subsection{6/oemed-2018-ICOHabstracts. 1076}

Introduction In Japan, all workers are required by law to receive annual health checkups. Annual health checkups are composed of health-based interviews (focused on subjective and objective complaints, anamnesis, and work history, for example), laboratory tests, chest X-rays, and ECG. Because interview sheets are not standardised, they are unique to each hospital. The aim of this study is to clarify the variety of interview sheets and to consider the issues surrounding them.

Methods We requested interview sheets from each hospital with cooperation from the National Federation of Industrial Health Organisation. We investigated the items that were asked in each sheet.

Results We received 70 interview sheets. Excluding six sheets because of duplication, we analysed 64 interview sheets. Sixtytwo sheets asked about anamnesis (96.9\%), 61 asked about subjective and objective complaints (95.3\%), and 26 asked about work history $(40.6 \%)$. There were no items that were asked on all interview sheets. There were 305 detailed items of anamnesis in total. Four sheets asked about working hours, three sheets asked about overtime hours, and six sheets asked about hazardous work.

Discussion Anamnesis, subjective and objective complaints, and work history are the items designated to interview sheets by law, but there were only a few sheets containing all these items. The purpose of annual health checkups is not only to detect diseases, but also to determine whether working environments are suitable for workers' health conditions. For this reason, these items are very important but most sheets do not include it. Subjective and objective complaints were asked for in most sheets, but details of it differed across sheets. Lifetime health management and comparisons of health checkup results are difficult because of non-standardised interview sheets. We suggest the standardisation of interview sheets in the future.

\section{CANCER INCIDENCE IN SWEDISH FIREFIGHTERS - PRELIMINARY RESULTS OF AN EXTENDED FOLLOW-UP OF THE NOCCA STUDY}

${ }^{1} \mathrm{C}$ Bigert*, ${ }^{2} \mathrm{Il}$ Martinsen, ${ }^{1} \mathrm{P}$ Gustavsson, ${ }^{3} \mathrm{P}$ Sparén. ${ }^{1}$ Institute of Environmental Medicine, Karolinska Institutet, Stockholm, Sweden; ${ }^{2}$ Cancer Registry of Norway, Oslo, Norway; ${ }^{3}$ Department of Medical Epidemiology and Biostatistics, Karolinska Institutet, Stockholm, Sweden

10.1136/oemed-2018-ICOHabstracts. 1077

Introduction Firefighters may be exposed to a wide range of carcinogens by inhalation or dermal exposure. They also work shift which may disrupt the circadian rhythm. Previous studies have been inconsistent concerning cancer risks among 